Prepared for the U.S. Department of Energy under Contract DE-AC05-76RL01830

\title{
Report on the NGS3 Working Group on Safeguards by Design for Aqueous Reprocessing Plants
}

S Johnson

$M$ Ehinger

M Schanfein

February 2011

Pacific Northwest

NATIONAL LABORATORY

Proudly Operated by Battelle Since 1965 


\title{
DISCLAIMER
}

This report was prepared as an account of work sponsored by an agency of the United States Government. Neither the United States Government nor any agency thereof, nor Battelle Memorial Institute, nor any of their employees, makes any warranty, express or implied, or assumes any legal liability or responsibility for the accuracy, completeness, or usefulness of any information, apparatus, product, or process disclosed, or represents that its use would not infringe privately owned rights. Reference herein to any specific commercial product, process, or service by trade name, trademark, manufacturer, or otherwise does not necessarily constitute or imply its endorsement, recommendation, or favoring by the United States Government or any agency thereof, or Battelle Memorial Institute. The views and opinions of authors expressed herein do not necessarily

state or reflect those of the United States Government or any agency thereof.

\author{
PACIFIC NORTHWEST NATIONAL LABORATORY \\ operated by \\ BATTELLE \\ for the \\ UNITED STATES DEPARTMENT OF ENERGY \\ under Contract DE-AC05-76RL01830
}

Printed in the United States of America
Available to DOE and DOE contractors from the Office of Scientific and Technical Information,
P.O. Box 62, Oak Ridge, TN 37831-0062;
ph: (865) 576-8401
fax: (865) 576-5728
email: reports@adonis.osti.gov

\author{
Available to the public from the National Technical Information Service, \\ U.S. Department of Commerce, 5285 Port Royal Rd., Springfield, VA 22161 \\ ph: (800) 553-6847 \\ fax: (703) 605-6900 \\ email: orders@ntis.fedworld.gov \\ online ordering: http://www.ntis.gov/ordering.htm
}

This document was printed on recycled paper. 


\section{Report on the NGS3 Working Group on Safeguards by Design for Aqueous Reprocessing Plants}

S Johnson

M Ehinger

M Schanfein

February 2011

Prepared for

the U.S. Department of Energy

under Contract DE-AC05-76RL01830

Pacific Northwest National Laboratory

Richland, Washington 99352 


\title{
The Third International Meeting for Next Generation Safeguards
}

\author{
December 14-15, 2010 \\ Washington, D.C.
}

\section{Report on the NGS3 Working Group on Safeguards by Design \\ For Aqueous Reprocessing Plants}

\author{
Topic: $\quad$ Safeguards by Design (SBD) \\ Working Group: Aqueous Reprocessing Plants \\ Moderator: $\quad$ Mark Schanfein (Idaho National Laboratory) \\ Document Leads: $\quad$ Shirley Johnson (Tucker Creek Consulting) \\ Mike Ehinger (Oak Ridge National Laboratory) \\ Note-takers: $\quad$ Danielle Miller (PNNL, NNSA) \\ David Peranteau (MELE, NNSA/NA-24) \\ Participants: $\quad$ Jean-Louis Carbonnier (CEA) \\ Peter Chare (Euratom, European Commission) \\ Ron Cherry (DOE/NNSA/NA24-DOS) \\ Joe Damico (SNL) \\ Dorothy Davidson (AREVA, North America) \\ Gregory Dupuy (PNNL, NNSA) \\ Stephen Francis (UK-NNL) \\ Tomonori Iwamoto (JNFL) \\ Tom Killeen (IAEA, SGCP) \\ Erwin Kuhn (IAEA, Retired) \\ Yusuke Kuno (JAEA) \\ Chris Phillips (Energy Solutions) \\ Jon Sanborn (DOS) \\ Marius Stein (AREVA, Canberra) \\ Larry Satkowiak (ORNL)
}





\section{Contents}

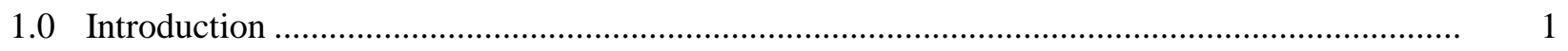

2.0 Working Group Opening and Presentations ................................................................... 3

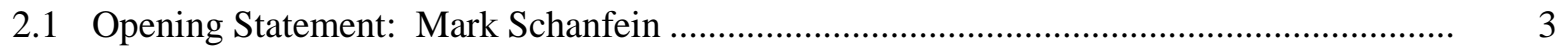

2.2 "Safeguards by Design"-Some Thoughts by AREVA: Marius Stein ............................. 3

2.3 Euratom Safeguards - Reprocessing: Peter Chare .......................................................... 3

2.4 Designing and Operating Aqueous Reprocessing for "Safeguardability"-Some

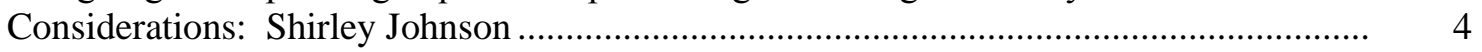

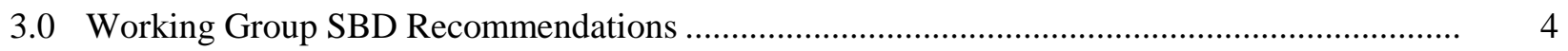

3.1 Capabilities For and Ease of Design Examination and Verification ................................. 5

3.2 Designing in Nuclear Materials Accountancy and Verification Systems .............................. 6

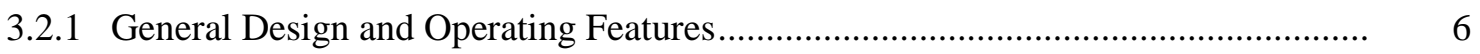

3.2.2 Operator Nuclear Material Accountancy System................................................ 7

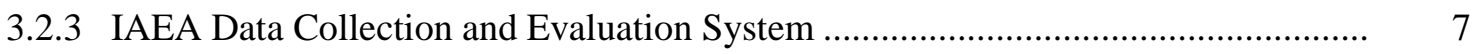

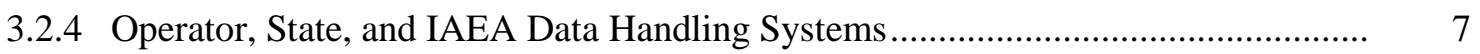

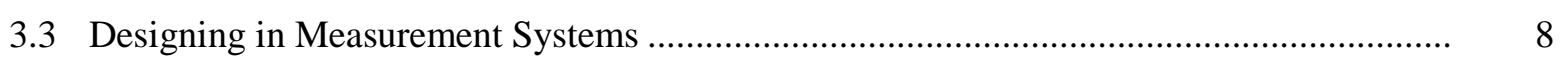

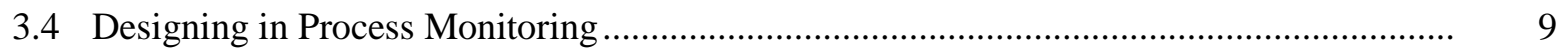

3.5 Designing in Sampling and Analytical Capabilities....................................................... 9

3.6 Designing in System Security and Authentication ........................................................... 10

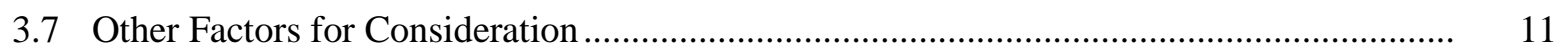

4.0 Summary of Conclusions and Recommendations ........................................................... 12

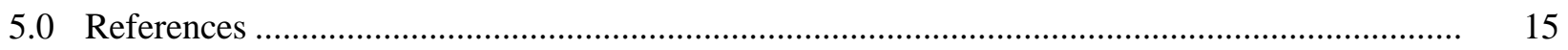




\subsection{Introduction}

The Third International Meeting on Next Generation Safeguards (NGS3) was held on December 1415, 2010 in Washington, D.C., and focused on the Safeguards by Design (SBD) concept. The International Atomic Energy Agency (IAEA) has described the SBD concept as an approach in which "international safeguards are fully integrated into the design process of a new nuclear facility from the initial planning through design, construction, operation, and decommissioning." To establish a global norm for the use of SBD, the United States (U.S.) Department of Energy (DOE) has initiated a project by way of its Next Generation Safeguards Initiative (NGSI). The NGSI SBD program is being developed in parallel with a similar effort at the IAEA, taking into account the IAEA's SBD achievements and future plans ${ }^{1}$. The NGSI program is pursuing the establishment of a SBD global norm through DOE laboratory studies, international workshops, engagement with industry and the IAEA, and setting an example through its use in new nuclear facilities in the U.S.

The IAEA currently conducts routine safeguards inspections at two reprocessing plants in Japan - the Tokai Reprocessing Plant (TRP) ${ }^{2,3,4}$ and the Rokkasho Reprocessing Plant (RRP) ${ }^{5,6,7}$. When these facilities are in full operation the IAEA implements a continuous inspection approach. This approach can currently require up to $20 \%$ of the Safeguards Department's total inspection effort. The IAEA also carries out inspections on a limited basis at reprocessing plants in France (La Hague), the United Kingdom (THORP), and India (Prefre) when these facilities are handling spent fuel from agreed sources (e.g., La Hague reprocesses spent fuel from reactors in Japan). A number of countries have announced plans for possible future construction of reprocessing plants. Japan may build another plant, which would be inspected under their INFCIRC 153 agreement. India may build a plant that possibly could be inspected under their INFCIRC 66 agreement, while the U.S. and China potentially could offer future reprocessing plants for inspection under their Voluntary Offer Agreements (VOA). The IAEA also may be called on to implement verification approaches for reprocessing plants under disarmament treaties, such as the Fissile Materials Cut-off Treaty (FMCT) ${ }^{8}$. If safeguards were implemented at the level currently applied in Japan, these expansions would require a dramatic increase in resource demand-well beyond current IAEA capabilities. The "first-line" effort in reducing these resource requirements while increasing facility transparency is designing safeguardability into the plant.

The Working Group on Safeguards by Design for Aqueous Reprocessing Facilities' objective was to provide recommendations for facility owner/operators and designers that would aid in the coordination and integration of nuclear material accountancy and the safeguards requirements of all concerned parties - operators, State/regional authorities, and the IAEA. The recommendations, which will be provided to the IAEA, are intended to assist in optimizing facility design and operating parameters to provide for the safeguardability of the facility while minimizing impact on the operations. The one-day working group session addressed a wide range of design and operating topics. These topics can be generally categorized as follows:

- Physical design and its "verifiability"

- Facility nuclear materials accountancy measures

- Transparency of operations and operating procedures

- Accommodation and accessibility for inspectors

- Plant administration and safeguards culture.

This paper will report on the discussion topics and present details of the NGS3 Aqueous Reprocessing Plant Working Group's final recommendations. 



\subsection{Working Group Opening and Presentations}

\subsection{Opening Statement: Mark Schanfein (Idaho National Laboratory)}

Participants were welcomed to the reprocessing working group by the group moderator, Mark Schanfein, who expressed appreciation for the great distances traveled to support this effort. The working group's schedule was reviewed with particular emphasis placed on the need to have a draft document generated within the scheduled time that contained specific and useful recommendations. He emphasized that there were no preconceived positions on this topic and all comments would be welcomed. He also stated that it was expectation that there would be and overlap in input from the four working groups. However, the document leads, Shirley Johnson and Mike Ehinger, would undertake final sorting and regrouping of the input to produce a more focused document that would be distributed to all Working Group participants for comments. Along with the document leads, note takers, Danielle Miller and David Peranteau, also were introduced.

\section{2 "Safeguards by Design"-Some Thoughts by AREVA: Marius Stein (AREVA, Canberra)}

Safeguards by Design is not new for AREVA. It is an integral part of the design and construction process. The IAEA Safeguards Approach needs to be established prior to the final design and start of construction in order to insure that all systems are integrated and operational during commissioning. For a complex facility such as reprocessing, it is extremely important to engage all participants. A corporate investor will be involved with an architect/engineer, multiple construction contractors, and the owner/operator who will commission and operate the facility. Domestic and international safeguards must be part of this design process. A primary basis for international safeguards is the verification of the declared material flows, inventory, and facility operations as reported though the State/Regional System for Accountancy and Control (SSAC/RSAC) to the IAEA. The role of domestic safeguards is essential in assuring the accuracy of declarations. It is recognized that the IAEA has limited resources and as a result it can be challenging to maintain dialog over the entire period of a long-term design and construction effort of a complex facility (e.g., reprocessing). SBD requires a balanced approach with all stakeholders involved to verify that safety, safeguards, and process controls are integrated. The focus of this presentation was that there is an immediate need to define and improve the design requirement of the IAEA and to verify that those requirements will have sufficient accessibility and flexibility for the future.

During the design stage of any nuclear facility, an integrated, life-of-plant approach is necessary to implement international safeguards-related requirements, optimize inspector access and activities, and facilitate the generation and handling of safeguards-relevant data while minimizing any adverse impact on normal operations.

\subsection{Euratom Safeguards-Reprocessing: Peter Chare (Euratom, European Commission)}

The presentation showcased Euratom's implementation of safeguards in reprocessing plants in the United Kingdom (Sellafield/THORP) and France (La Hague). Euratom found it necessary to revise its verification approach schemes because of the need to reduce human resource requirements. Euratom is now moving toward remote data collection with transfer to its Luxembourg headquarters for data 
analysis. The presentation then reviewed typical plant operations, usual process equipment, and process streams important to the inspection process.

Euratom conceptualizes the process area as a "black box" technology, focusing monitoring activities on the input and output measurements, not necessarily the processes within. These are traditional accountancy measurements for flow verification. Volume measurements combined with inspector sample collections are used. Weight measurements are made on solid product materials and usually are complemented with containment and surveillance. Non-destructive Analysis (NDA) techniques are applied in product storage areas to confirm identity and quantity of plutonium $(\mathrm{Pu})$ in packages as they enter. A form of flow sheet verification is applied for verification of operation as declared.

For the head-end and main process areas, the safeguards approach is based on material accountancy and evaluation of the Material Unaccounted For (MUF) at inventory closure periods. The audit of reported measurements relies on independent verification measurements. The Physical Inventory Verification (PIV), along with MUF and sigma-MUF evaluation, is conducted on an annual basis. The annual evaluation is complemented with monthly Interim Inventory Verifications (IIV). Additionally, the containment and surveillance review of the storage areas are important components.

\subsection{Designing and Operating Aqueous Reprocessing for "Safeguardability"-Some Considerations: Shirley Johnson (Tucker Creek Consulting)}

This presentation introduced the working group's draft guidance document, "Draft Safeguards by Design for Aqueous Reprocessing Plants" and provided an overview of the topical areas to be discussed. The presentation also provided background information ${ }^{9,10}$, as well as explanations related to the design recommendations featured in the working group guidance document.

\subsection{Working Group SBD Recommendations}

The working group's objective on SBD for aqueous reprocessing plants was to discuss and record recommendations for provision to the IAEA that would assist in establishing a set of guidance documents for facility operators and designers. The purpose of the design recommendations is to aid in the coordination and integration of nuclear material accountancy and safeguards requirements of all concerned parties: owner/operator/designers, State/regional authorities, and the IAEA. The recommendations propose an optimization of the facility design and operating parameters to enhance the "safeguardability" of a facility. The recommendations also are designed to establish an effective and efficient safeguards system that can be implemented on a schedule consistent with construction and commissioning of a reprocessing plant within the resource capabilities of the operator, State and IAEA. The working group's recommendations covered various design and operating topics, including:

- Physical design and its "verifiability"

- Facility nuclear materials accountancy measures

- Transparency of operations and operating procedures 
- Accommodation and accessibility for inspectors

- Plant administration and safeguards culture.

\subsection{Capabilities For and Ease of Design Examination and Verification}

The IAEA's design information examination and verification begins with pre-construction activities and continues through construction and commissioning, operation, and shutdown/closed-down until the facility has been verified as "decommissioned for safeguards purposes" IAEA to be present during activities that might impact the design of the facility and are relevant to the Safeguards Approach, the operator should provide an updated operational schedule on a continuing basis.

During the early life cycle phases of a facility, e.i. pre-construction, construction and commissioning, close communications are needed between the designer, owner/operator, State and the IAEA. A design team should be established with representatives from all concerned parties. Synergies between safeguards, safety, security and criticality control requirements should be identified and their impact on plant design addressed. Enhanced understanding of each party's needs and concerns could be achieved through a mutual training program.

The provision of design information that is highly sensitive due to commercial and/or proliferation concerns must be minimized. However, this situation should be expected. As such, a possible solution could be storage of the information in an operator-controlled area under both IAEA and State seals.

Inspector access for design verification to areas of the plant that will have no access (e.g. concrete pours) or limited access (e.g. enclosed trenches and process cells) after construction must be considered during the pre-construction and construction phases. And, if possible, provisions should be made for the continuing design verification of selected strategic cells. To increase assurance that no changes are made to safeguards-relevant design features, the possible use of remote viewing devices or access during maintenance times should be considered. This may require the development of new or improved verification tools that can access "difficult to access" locations for re-verification of cells and pipes.

To better understand the design, operation, and measurement capabilities of the primary accountancy vessels ( the Input and Output Accountability Tanks (IAT/OAT)), selected high-inventory vessels, and difficult-to-measure vessels and equipment (evaporators and separators) it is recommended that to-scale copies be built at a demonstration facility prior to construction and installation in the plant. The availability of demonstration vessels and equipment would allow for the optimization of the internal structures for calibration concerns, testing of the homogenization capabilities, realization of effects of environmental controls, and validity of the sampling system. For difficult-to-measure vessels, it would provide an opportunity to develop and verify inventory hold-up algorithms. Access to the demonstration/test facility would not only be beneficial to the designer and operator, but also to State and international authorities.

Consideration must be given to the IAEA's requirement to perform yearly or periodic recalibrations or calibration checks on selected inventory and inventory change vessels. The installation and use of permanent calibration systems and standardized procedures during the initial calibrations of selected vessels would afford more controlled and reproducible conditions during future calibration activities. 


\subsection{Designing in Nuclear Materials Accountancy and Verification Systems}

\subsubsection{General Design and Operating Features}

The general design and operations should incorporate clear and identifiable boundaries that will assist in establishing Material Balance Areas (MBA), Inventory Key Measurement Points (IKMP), and Flow Key Measurement Points (FKMP). Therefore, it is important that the facility owner/operator, State and IAEA agree on the number and location of MBAs and KMPs early in the design process.

Plant operations can have a large impact on the ease and transparency of a Nuclear Materials Accountancy (NMA) system. The use of batch transfers between vessels within the process, where and when possible, facilitate the taking and verification of the in-process inventory and inventory changes of an operating plant. Using batch transfers also reduces the amount of inventory hold-up in piping and provides clearer boundaries for inventory measurements and declarations at the time of Interim Inventory Verification (IIV).

Plant operations and NMA should be designed to track nuclear material throughout the plant and be capable of providing inventory declarations on short notice. The facility NMA system should include effective measurement control procedures to rapidly assess and internally review and approve accountancy measurements for declarations to the State/regional authorities for transmittal to the IAEA. This will be of increased importance if the IAEA uses an electronic mailbox at reprocessing facilities in the future. Operator declarations may need to be provided in near real time to the IAEA or through the State authority (as agreed).

Efforts are needed to minimize un-measureable inventory (UMI) in locations such as pipes, pumps, evaporators, and separators. This may include avoiding long distances between buildings with piping through non-accessible trenches. To minimize UMI, facilities should be designed compactly and without excessive piping (where possible). However, despite these efforts, it is understood that a facility cannot completely avoid UMI. Therefore, the recommendation is to minimize UMI, and, where it is not possible, algorithms must be developed. Other considerations to address UMI include:

- Construct scale-model tests to develop algorithms

- Estimate hold-up from engineering designs

- Test and confirm UMI values during commissioning

- Design in ways to allow pipes and pumps to drain, and establish the receiving MBA.

Design consideration also must be given to nuclear material rework and chemical recycle capabilities to assure that they are transparent and available for verification. Misuse or undeclared use of these auxiliary processes is a safeguards concern. Therefore, access and verification in these areas increases confidence that the facility is being operated as declared.

Both liquid- and solid-waste handling and treatment areas should be designed so they are clearly segregated and defined and should include a detailed waste-tracking system that documents the origin of 
all waste batches. This capability may be required for the operator to determine waste quantities for accountancy declarations and the implementation of IAEA verification procedures.

Inspectors may require short notice random access to agreed safeguards-relevant operating data, information, or equipment to increase assurance that a facility is being operated as declared. These access requirements should be established early so operating procedures, such as security and safety, can accommodate them.

\subsubsection{Operator Nuclear Material Accountancy System}

The operator's nuclear material accountancy (NMA) system must be capable of meeting domestic safeguards requirements, as well as provide information to the State for submission to the IAEA. The NMA system and procedures must include appropriate measurement control activities and provide timely submission of flow and inventory declarations, including relevant source data, to the State and IAEA. The system also should provide agreed operating information, such as operating status, schedules, and process disruptions ${ }^{12}$.

The NMA system must have timely access to operating and in-plant accounting data. As such, the design of the NMA system must be considered in the facility's early design stages and be coordinated with the plant operations design as well as State authority and IAEA requirements.

\subsubsection{IAEA Data Collection and Evaluation System}

Inspector verification data must be securely transmitted from the various inspector-installed and unattended measurement, monitoring, and surveillance stations within the facility to a central database, possibly in the local inspector's office and/or to the IAEA headquarters or regional office. IAEA data transmission requirements should be specified and considered in the design and construction of the plant. If off-site transmission of inspector verification data is anticipated to support short notice or remote inspections, it must be negotiated early and security considerations addressed. Additionally, how to handle operator proprietary information must be addressed early and built into the design of the Data Collection and Evaluation (DC\&E) system.

\subsubsection{Operator, State, and IAEA Data Handling Systems}

Design specifications for the integration of the operator's NMA system and the inspector's DC\&E systems must be included in the pre-construction phase as an integral part of the development of a safeguards approach, and the design and operation of the facility ${ }^{13}$. Interface control documents must be specified and agreed early. However, in order to prevent any threat of interference with plant operations or tampering of either system, physically connections between the inspector and operator's data systems should be avoided where possible. Data transmission within the facility should be on a high-speed network (hardwired and/or wireless) between all safeguards-related equipment. Network connections should be installed in all areas of the facility to support future technologies.

Data should include State of Health ( $\mathrm{SOH})$ information from all remote, unattended measurement and monitoring systems. In addition to data received from installed and unattended systems, the analytical 
results from accountancy and verification samples should be received in a timely manner from the relevant laboratories.

To reduce the human workload, the systems' software should be capable to doing reviews and extensive pre-evaluations of data in an automated and real-time mode. Pre-evaluations could include data quality checks, data correlations, consistency checks, and paired data comparisons. The system should automatically call attention to possible data discrepancies, schedule changes, completion of actions, and announce irregularities in the $\mathrm{SOH}$. The system also should allow for interactive reviews and "drilldown" capabilities to facilitate operator and inspector reviews and investigation of possible discrepancies. Report-ready summaries and evaluations should be provided for various stages of the accounting and verification process.

\subsection{Designing in Measurement Systems}

To reduce on-site inspector presence, unattended measurement and monitoring systems should be installed, where possible, for verification of operator declarations and assurance that the facility operations are as declared. Constraints may dictate that installed measurement systems must be jointly used by the IAEA and State and possibly the operator. Early consultation between all parties and the system developers must start during the pre-construction phase. All joint-use systems must have security and/or authentication measures incorporated into their design. All IAEA systems, whether solely for IAEA use or joint-use, must have third-party vulnerability tests to verify tamper resistance/detection and validity of the acquired data. Particular attention must be given to both the State and IAEA requirements to reach independent conclusions.

The operator must implement measurement systems and a control program that confirms all accountancy data is in conformance with International Target Values (ITV) ${ }^{14}$ and meets facility specifications. The measurement control program should provide timely information on the performance of measurement systems, including documentation of statistical performance.

The design and operations of the plant must be such that a minimum number of samples need to be taken at the time of the inventory declaration and that the majority of inventory can be verified by in-

vessel measurement systems ${ }^{15}$, sample taking, or process design estimations. Moreover, that continuity of knowledge of the flowing inventory can be maintained from the time of the inventory declaration to the time of measurements.

During the pre-construction phase of a facility, the responsibilities for the design, procurement, installation, operations, and maintenance of inspectorate verification equipment must be agreed between the owner/operator, State, and IAEA.

The facility design should include the provision of an uninterruptible power supply for all safeguardsrelated equipment. Provisions for access to said power supply is recommended in all areas of the facility to support future technologies. 


\subsection{Designing in Process Monitoring}

The State and IAEA process monitoring (PM) systems, whether solely owned or jointly used, must provide independent verification of the operator's declarations and assurance that the facility is being operated as declared. These systems may include solution monitoring for volume and density, or the monitoring of specific elements or parameters of the process ${ }^{16,17}$. Additionally, if the agreed IAEA Safeguards Approach includes the implementation of Near-Real-Time-Accountancy (NRTA), the approach would require that the operator's accountancy and PM systems be designed with the capability of providing almost-immediate inventory declarations based on the best available accountancy and process data. The IAEA may chose to use independent PM systems or jointly use the operator PM systems to assist in meeting their goals for verification of the operator's declaration and for maintaining continuity of knowledge of the flow of nuclear material.

Installed PM systems may need to be designed with the capability of continuously monitoring the flow and storage of nuclear material from the spent fuel receipt and storage, through the head-end and separations process, and to the back-end conversion process and storage. The facility design and Safeguards Approach must be considered simultaneously to establish the required equipment and locations of the PM systems.

The operator's PM systems should be designed and operated for the purpose of providing timely information (and declarations) on the location and movements of nuclear material throughout the plant at any specified time.

The separation of alternative nuclear materials, such as neptunium, is monitored by the IAEA on a voluntary basis. The monitoring of neptunium using Flow Sheet Verification (FSV) ${ }^{18}$ also provides added assurance that the process is being operated as declared and may be included in the IAEA Safeguards Approach. The FSV would require the operator to establish during active commissioning and then declare the expected flow sheet for that element throughout the process, including waste streams. Installed measurement systems may also be required.

\subsection{Designing in Sampling and Analytical Capabilities}

Although installed unattended measurement systems would be the most desirable for providing accountancy and verification data, sample taking cannot be avoided. Sample taking is needed: to offset higher uncertainties associated with unattended measurement systems; for authentication of those systems; for use where on-line measurements are not possible; and as part of a Quality Assurance/Quality Control (QA/QC) program. Installed sampling systems and their effects on the validity of the samples must be considered as part of the plant design. The design criteria should take into consideration factors such as evaporation, homogenization, and sampling depth, as well as the capability of simultaneous sampling of multiple vessels. Operator sampling systems jointly used by the State and IAEA also must be designed to provide transparent operations, sample traceability, low tamper vulnerability with provisions for authentication, and high flexibility in the taking and scheduling of samples.

The IAEA usage needs and authentication requirements for a joint-use, operator-owned sampling system must be specified in the early design criteria. The sample authentication system ${ }^{19}$ and procedures that insure the integrity of empty and full inspector sampling vials must be addressed. The sampling 
system should be capable of tracking the sample vials from their introduction into the system, transfer to the process sampling location, and return to inspector control with high assurance that a valid and true sample has been obtained.

Early design considerations also must consider whether an on-site laboratory will be built for IAEA use or joint-use with the State ${ }^{20,21}$. Although an IAEA on-site laboratory requires a large financial and human resource commitment, it does provide a number of benefits:

- For the inspector

- Improved control of inspector samples and reduced chance of tampering

- Timely analytical results of equal quality to those of the IAEA's network laboratories or International Target Values (ITV)

- Large sample aliquots can be handled as compared to the dried samples sent to the IAEA Safeguards Analytical Laboratory (SAL) in Vienna, Austria

- Waste can be recycled back to the process

- Reduction in the cost of shipping samples to the SAL.

- For the operator

- Reduction of resource requirements for preparation of inspector samples

- Significant reduction of paperwork required for shipping inspector samples to SAL

- Reduction of operator responsibilities for handling inspector samples and chances of mishaps.

If a full-scale inspector laboratory is not required, other options could include use of the operator's laboratory for sample preparation and/or a limited selection of measurement systems. Use of the operator's laboratory and staff would require additional security and authentication measures for sample taking and measurements. These options must be considered while designing the operator's laboratory and operating procedures.

\subsection{Designing in System Security and Authentication}

To conserve financial resources and with consideration to physical space and access constraints in the plant, some measurement and monitoring systems may need to be installed and used jointly by the IAEA $^{22}$ and State inspectorates, and, in some instances, the operator ${ }^{23}$.

When designing and installing measurement or monitoring systems in a facility for joint-use, the following data security issues must be considered:

- Assurance that data has originated from a known source and has not been altered, removed, or substituted

- Assurance that data from joint-use systems cannot be used in such a way as to influence the accountancy and operational declarations by the operator to the inspectors 
- Assurance that the State cannot use knowledge of the systems and data in collaboration with the operator to defeat the implementation of reliable IAEA safeguards measures and investigations into possible discrepancies

- For unattended systems, a level of assurance comparable with other safeguards measures. An appropriate standard of encryption should be employed to confirm that sensitive information has originated from a known source and has not been altered, removed, or substituted.

IAEA authentication needs and requirements must be identified early to be incorporated into the design of the facility, operating procedures, and equipment. The IAEA may consider a number of methods in designing acceptable security and/or authentication for inspector use of installed and unattended measurement and monitoring systems. A few current examples include:

- Installed technical methods

- Hardware: Tamper-indicating enclosures (TIE) or sealed tamper-indicating enclosures (STIE); seals; camera surveillance; safeguards conduit; and motion, heat, or radiation sensors.

- Software: IPsec; "sign and forward" (SnF); varying levels of password control; delayed data access for operator/State; and other methods of data encryption.

- Procedural methods

- Portable cable testers, optical time domain reflectometers (OTDR), and portable pressure gauges

- Cross-correlation of data from a number of sources. This could be various sources for the same piece of data, or it could be related data from various sources, such as adjoining vessels

- Sealed standard containers and sealed sources

- Short notice random sample taking for independent analyses

- Short notice random visits by inspectors (observations or measurements).

\subsection{Other Factors for Consideration}

There are a number of other questions to consider when designing and operating a plant with the goal of enhancing its safeguardability, including the following:

- Where will the plant be located? What is its proximity to Vienna and the IAEA's SAL? What is the local availability of technical services? Will it be built in a Nuclear Weapon State (NWS) or a Nonnuclear Weapon State (NNWS)?

- Will the plant safety and security arrangements be able to accommodate short- or no-notice random inspections?

- How can the "planting and growing" of a safeguards culture be promoted and assured among the operating staff?

- What will be the educational and experience level and training requirements for the IAEA, operator and State safeguards staffs? 


\subsection{Summary of Conclusions and Recommendations}

1. The working group focused on the implementation of IAEA safeguards rather than the State/Regional Systems of Accountancy and Control (SSAC/RSAC) safeguards requirements. This allowed the group to work with more specific requirements, while keeping in mind that the results of the discussions could apply to other areas of safeguards regulation. The working group agreed that the current goal of Safeguards by Design (SBD) discussions and work is to establish guidelines and recommendations for plant designers and owners/operators. However, they should assist not only the designers and owners/operators but also the IAEA and SSAC/RSACs in understanding where and what the specific design concerns are. They should provide the basis for the IAEA and industry to discuss solutions.

2. There is a continuing need to improve the formality of the design process in order to enhance the SBD discussions between all concerned parties and to lead to a more efficient implementation of international safeguards. The SBD responsibilities particular to each party — designer, owner/operator, State, and IAEA — should be clarified. A description of activities conducted during the conceptual and preliminary design steps also needs to be clarified. These issues should be considered as future discussion points.

3. An SBD guidance document should avoid technical or design recommendations tied to a particular current-day technology or set of technologies that may not be relevant in the future. However, new technologies should exceed what is 'current' in the areas of sensitivity, unattended operations, reliability, robustness, ease of trouble-shooting and maintenance, and relative costs. The document should provide technological recommendations and prioritization of research and development $(R \& D)$ needs in the future. This type of information could assist designers and owners/operators in determining what $R \& D$ may be required to successfully introduce safeguardability into the facility design.

4. Unlike other types of facilities that may have standardized designs and are built in a number of different countries, new reprocessing plants are likely to be unique and customized for their respective host country. Therefore, SBD recommendations must account for the possibility of nonstandardization.

5. Guidance documents should recommend that safeguards-relevant design features are considered as early as possible in the design process. The preparation and official submittal of the Design Information Questionnaire (DIQ) by the operator/State does not take place early enough to provide an opportunity for the IAEA to participate in the design phase. Thus, there must be an informal provision of design plans and information at an early stage, in accordance with GOV/2554/Attachment 2/Rev.2 (1 April 1992) ${ }^{11}$ :

"Parties to comprehensive safeguards agreements will need to provide design information to the Agency at the time of the decision to construct, or to authorize the construction of, any nuclear facility (i.e., well before construction actually begins) in order to create confidence in the peaceful purpose of the facility and to provide adequate lead-time for safeguards preparations - more specifically:

(a) to facilitate the incorporation into the facility design - including the design of the nuclear materials accountancy system - of features which will make it easier to implement safeguards at the facility (any proposed design modifications being 
consistent with the prudent management practices required for the economic and safe operation of the facility and such as to avoid hampering or delaying construction, commissioning or operation);

(b) to allow time for safeguards research and development work that may be necessary;

(c) to enable the Agency to do the budgetary planning necessary for the effective and efficient implementation of safeguards; and

(d) to permit the identification and scheduling of actions which need to be taken jointly by the State, the facility operator and the Agency, including

(i) the installation of safeguards equipment during construction of the facility; and

(ii) the verification of information on the design of the facility."

6. Minimizing the amount of un-measureable inventory (UMI) was recognized as a design priority for reprocessing plants. Because UMI cannot be totally eliminated, early testing must be conducted to quantitatively estimate it via proven and verifiable algorithms.

7. During the design phase, on-site analytical capabilities, whether destructive (DA) or non-destructive (NDA) analyses, must be considered for IAEA use. These capabilities could include the: 1) introduction of an independent inspector laboratory, 2) installation of unattended measurement and monitoring systems, and/or 3) joint-use of State or operator facilities and equipment. Early consideration should be given to a cost-benefit analysis evaluating inspector presence to carry out measurements versus complex unattended systems.

8. From an SBD perspective, maximizing joint-use equipment is desirable. The advantages and disadvantages of joint-use equipment must be assessed prior to construction, giving particular attention to system security and authentication which the IAEA will require to reach independent conclusions.

9. The large and growing volume of safeguards data that will be produced at reprocessing facilities drives a number of safeguards requirements and design considerations, including the need to automate data generation, pre-evaluation, reporting, authentication, encryption, etc. Due to the size and complexity of these data management systems, their design requirements must be incorporated into the overall plant design. Data transmission within the facility (and possibly off-site) also must be considered, which will require early negotiations on security issues.

10. The design team needs to be a coalition of people, including the owner/operator, designer, State, and IAEA. A possible recommendation would be that the IAEA draw temporary staff from the owner/operator design team. Moreover, the design team should make an effort to hire some staff with safeguards background or expertise. This approach could enhance communication between the parties.

11. An important step for the IAEA would be to establish a training course for design organizations -those that are considering designing and/or building plants or have contracts to do so -- which would provide an understanding of "What is safeguards?" and "What are the basic elements that effect plant design?" The IAEA also should consider ways to keep designers abreast of changes and new safeguards requirements.

12. There are many synergies between the SBD efforts and those associated with safety, security, and criticality control. Plant designers have regular contact with the IAEA's Department of Nuclear 
Energy and Nuclear Safety. However, there is little contact with the Safeguards Department. The Safeguards Department should make an effort to network through these other departments to determine where they can collaborate to avoid duplication of effort. 


\subsection{References}

${ }^{1}$ IAEA - International Atomic Energy Agency. Facility Design and Plant Operation Features that Facilitate Implementation of IAEA Safeguards. IAEA Report STR-360, IAEA, Vienna, Austria. February 2009.

${ }^{2}$ S.J. Johnson and A. Islam. "Current IAEA Approach to Implementation of Safeguards in Reprocessing Plants." Proceedings of the Fourth International Conference on Facility Operations - Safeguards Interface, Albuquerque, NM. 1991.

${ }^{3}$ T. Shea, S. Deron, F. Franssen, D. Hope, N. Islam, S. Johnson, E. Kuhn, G. Laszlo, D. Neal, and T. Renis. "Safeguarding Reprocessing Plants: Principles, Past Experience, Current Practice and Future Trends." Journal of the Institute of Nuclear Materials Management 21(4):17-28. 1993.

${ }^{4}$ S.J. Johnson, T. Shea, and A. Ratchev. "A Safeguards Improvement Plan for Reprocessing Plants (Task 9)." Proceedings of the Symposium on International Safeguards. IAEA-SM-351/143, International Atomic Energy Agency (IAEA) Symposium on International Safeguards, IAEA, Vienna, Austria. 1997.

${ }^{5}$ S.J. Johnson, R. Abedin-Zadeh, C. Pearsall, B. Chesnay, C. Creusot, M. Ehinger, E. Kuhn, N. Robson, H. Higuchi, S. Takeda, K. Fujimaki, H. Ai, S. Urhara, H. Amano, and K. Hoshi. "Development of the Safeguards Approach for the Rokkasho Reprocessing Plant." Symposium on International Safeguards: Verification and Nuclear Material Security, Book of Extended Synopses. IAEA-SM-367/8/01, IAEA, Vienna, Austria. 2001.

${ }^{6}$ S.J. Johnson, B. Chesnay, C. Pearsall, S. Takeda, H. Tomikawa, K. Fujimaki, and T. Iwamoto. "Meeting the Safeguards Challenges of a Commercial Reprocessing Plant." Proceedings of the $7^{\text {th }}$ International Conference on Facility Operations/Safeguards Interface, Charleston, SC. 2004. And Record of Proceedings (pp. 8-16), 25th Annual Meeting of the Institute of Nuclear Materials Management, Japan Chapter, Rokkasho, Aomori, Japan. November 2004.

${ }^{7}$ S.J. Johnson. "Reprocessing Facilities: The Technical Challenges for International Safeguards." Proceedings of the $47^{\text {th }}$ Annual INMM Meeting, Nashville, TN. July 2006.

${ }^{8}$ Shirley Johnson. The Safeguards at Reprocessing Plants under a Fissile Material (Cutoff) Treaty. Research Report No.6, International Panel on Fissile Materials, Princeton, NJ. February 2009.

${ }^{9}$ Michael H. Ehinger, Shirley J. Johnson. Lessons Learned in International Safeguards - Implementation of Safeguards at the Rokkasho Reprocessing Plant. ORNL/TM-2010/23, Oak Ridge, TN. December 2009.

${ }^{10}$ S.J. Johnson, M. Ehinger. Designing and Operating for Safeguards: Lessons Learned From the Rokkasho Reprocessing Plant (RRP). PNNL-19626, Richland, WA. August 2010.

${ }^{11}$ IAEA - International Atomic Energy Agency. International Atomic Energy Agency: Strengthening of Agency Safeguards: The Provision and Use of Design Information. IAEA Board of Governors Report, \#GOV/2554/Attachment 2 (Revision 2), Vienna, Austria. April 1992. 
${ }^{12}$ J. Wuester, B. Chesnay, G. Gerrein, K Hiruta, M Suzuki and Y Yamazaki. "Automating the Operator Interface - Operator Declarations at RRP." Proceedings of the $7^{\text {th }}$ International Conference on Facility Operations-Safeguards Interface (pp.167-176), Charleston, SC. 2004.

${ }^{13}$ Joseph P. Damico, Florin Abazi, Charles Pearsall, Jan Wuester. "The Integrated Inspector Information System for the Rokkasho Reprocessing Plant." Proceedings of the 46th Annual Meeting of the Institute of Nuclear Materials Management, Phoenix, AZ. July 2005.

${ }^{14}$ K. Zhao, et.al.. International Target Values 2010 for Measurement Uncertainties in Safeguarding Nuclear Materials. IAEA STR-294, IAEA, Vienna, Austria. November 1994.

${ }^{15}$ L.E. Smith, J.M. Schwantes, J.J. Ressler, M. Douglas, K.A. Anderson, C.G. Fraga, P.C. Durst, C.R. Orton, and R.N. Christensen. "Next-Generation On-Line MC\&A Technologies for Reprocessing Plants." Global 2007, Advanced Nuclear Fuel Cycles (pp. 1657-1666). American Nuclear Society, La Grange Park, IL. 2007.

${ }^{16}$ M. Ehinger, B. Chesnay, C. Creusot, and J. Damico. "Solution Monitoring Applications for the Rokkasho Reprocessing Plant." Proceedings of the $7^{\text {th }}$ International Conference on Facility OperationsSafeguards Interface (pp. 139-146), Charleston, SC. 2004.

${ }^{17}$ Kevin Whitehouse, Eleanor Carr, Doug, Graham Morris, Keith Tolk. "PIMS for Safeguards Measurements at Rokkasho Processing Plant." Proceedings of the $7^{\text {th }}$ International Conference on Facility Operations-Safeguards Interface (pp. 155-166), Charleston, SC. 2004.

${ }^{18}$ Note: Recommendations for Flow Sheet Verification made in SAGSI Report SAR-30 and the IAEA Board of Governors paper GOV/1999/19.

${ }^{19}$ C. Creusot, G. Duhamel, K. Tolk, S. Takeda, and S. Masuda. "Control and Tracking of Unattended Sample Taking for Safeguards Purposes at the Rokkashomura Reprocessing Plant (RRP)." Proceedings of the $7^{\text {th }}$ International Conference on Facility Operations/Safeguards Interface (pp. 147-153), Charleston, SC. 2004.

${ }^{20}$ G. Duhamel, E. Kuhn, P. Zahradnik-Gueizelar, Y. Kuno, T. Nakaya, S. Takeda, T. Iwamoto, S. Nakashima, Y. Tokai, M. Iwanaga, and Y. Tsutaki. "Establishing the Joint IAEA/JSGO/NMCC Safeguards On Site Laboratory for the Rokkasho Reprocessing Plant: a Major Challenge for Managing the Interfaces. $7^{\text {th }}$ International Conference on Facility Operations - Safeguards Interface (pp. 127-138), Charleston, SC. 2004.

${ }^{21}$ P. Zahradnik-Gueizelar, E. Kuhn, S. Johnson, G. Duhmel, Z. Radecki, and Y. Kuno. "Authentication and Sample Chemistry: A New Approach at the Rokkasho Reprocessing Plant On-Site Laboratory." Proceedings of the IAEA International Safeguards Symposium on Addressing Verification Challenges, IAEA-CN-148-105 (pp. 681-688), IAEA, Vienna, Austria. October 2006.

${ }^{22}$ K. Tolk, M. Aparo, C. Liquori, and A. Capel.. "Design of Safeguards Systems for Authentication." Proceedings of the IAEA International Safeguards Symposium on Addressing Verification Challenges, IAEA-CN-148/82 (pp. 476-481), IAEA, Vienna, Austria. 2006.

${ }^{23}$ K. Tolk and P. Merkle, and M. Aparo. "The Impact of Safeguards Authentication Measures on the Facility Operator." Proceedings of the $8^{\text {th }}$ International Conference on Facility Operations - Safeguards Interface (pp. 476-481), Portland, OR. 2008. 


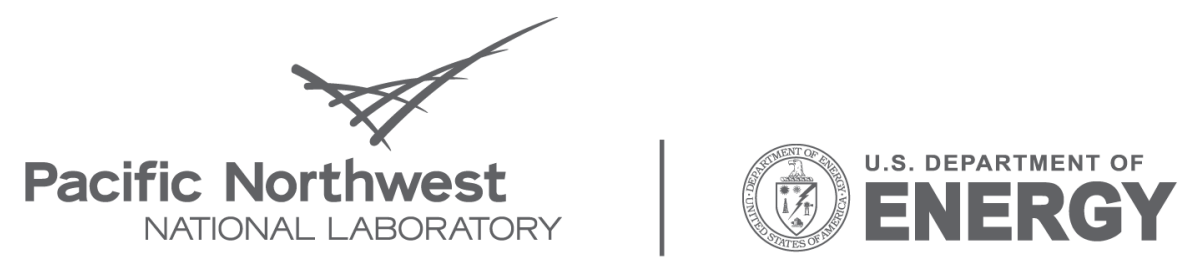

Proudly Operated by Battelle Since 1965

902 Battelle Boulevard

P.O. Box 999

Richland, WA 99352

1-888-375-PNNL (7665)

www.pnl.gov 